\title{
Polymorphisms in K13, pfcrt, pfmdr1, pfdhfr, and pfdhps in parasites isolated from symptomatic malaria patients in Burkina Faso
}

\author{
Anyirékun Fabrice Somé ${ }^{1, *}$, Hermann Sorgho ${ }^{2, *}$, Issaka Zongo ${ }^{1}$, Thomas Bazié ${ }^{1}$, Frédéric Nikiéma ${ }^{1}$, \\ Amadé Sawadogo ${ }^{1}$, Moussa Zongo ${ }^{1}$, Yves-Daniel Compaoré ${ }^{1}$, and Jean-Bosco Ouédraogo ${ }^{1}$ \\ 1 Institut de Recherche en Sciences de la Santé, Direction Régionale de l’Ouest, 399 Avenue de la liberté, 01 BP 545, \\ Bobo-Dioulasso 01, Burkina Faso \\ 2 Institut de Recherche en Sciences de la Santé, Unité de Recherche Clinique de Nanoro, BP 218 Ouaga CMS 11, Burkina Faso
}

Received 2 September 2016, Accepted 6 December 2016, Published online 22 December 2016

\begin{abstract}
Background: The emergence of resistance to artemisinin derivatives in western Cambodia is threatening to revert the recent advances made toward global malaria control and elimination. Known resistance-mediating polymorphisms in the K13, pfcrt, pfmdrl, pfdhfr, and pfdhps genes are of greatest importance for monitoring the spread of antimalarial drug resistance. Methods: Samples for the present study were collected from 244 patients with uncomplicated malaria in health centers of Bobo-Dioulasso, Burkina Faso. Blood sample was collected on filter paper before the subject received any treatment. The parasite DNA was then extracted and amplified by Polymerase Chain Reaction (PCR) to evaluate the prevalence of polymorphism of pfcrtK76T, pfmdrl (N86Y, Y184F), and pfdhps (A437G, K540E). The K13 gene polymorphism was analyzed by nested PCR followed by sequencing. Results: The overall results showed 2.26\% (5/221) of K13 synonymous mutant alleles (two C469C, one Y493Y, one G496G, and one V589V), $24.78 \%, 19.58 \%, 68.75 \%, 60.9 \%, 53.7 \%, 63.8 \%$, and $64.28 \%$, respectively, for mutant pfcrt $76 T$, pfmdr186Y, pfmdr1-184F, pfdhfr51I, pfdhfr59R, pfdhfr108N, and pfdhps 437G. We did not report any mutation at codon 540 of pfdhps. Conclusion: These results provide baseline prevalence of known drug resistance polymorphisms and suggest that artemisinin combination therapies may retain good efficacy in the treatment of uncomplicated malaria in Burkina Faso.
\end{abstract}

Key words: Plasmodium falciparum, k13, pfcrt, pfmdrl, dhfr, dhps, artemisinin resistance.

Résumé - Polymorphismes de K13, pfcrt, pfmdr1, pfdhfr et pfdhps chez des parasites isolés de patients symptomatiques de paludisme au Burkina Faso. Contexte: L'émergence de la résistance aux dérivés de l'artémisinine dans l'ouest du Cambodge menace d'annuler les avancées récentes en matière de lutte et d'élimination du paludisme à l'échelle mondiale. Les polymorphismes de médiation de résistance connus dans les gènes K13, pfcrt, pfmdrl, pfdhfr et pfdhps sont de la plus grande importance pour surveiller la propagation de la résistance aux antipaludiques. Méthodes: Les échantillons de cette étude ont été prélevés sur 244 patients atteints de paludisme non compliqué dans les centres de santé de Bobo-Dioulasso, au Burkina Faso. Les échantillons de sang ont été prélevés sur du papier filtre avant que le sujet ne reçoive aucun traitement. L'ADN du parasite a ensuite été extrait et amplifié par PCR pour évaluer la prévalence du polymorphisme de pfcrtK76T, pfmdrl (N86Y, Y184F) et pfdhps (A437G, K540E). Le polymorphisme du gène K13 a été analysé par PCR imbriquée suivie d'un séquençage. Résultats : Les résultats globaux ont montré $2.26 \%$ d'allèles mutants $(5 / 221)$ pour $K 13$ (deux C469C, un Y493Y, un G496G et un V589V), et $24.78 \%, 19.58 \%, 68.75 \%, 60.9 \%, 53.7 \%, 63.8 \%$ et $64.28 \%$, respectivement, pour les mutants pfcrt 76T, pfmdr1-86Y, pfmdr1-184F, pfdhfr51I, pfdhfr59R, pfdhfr108N et pfdhps 437G. Nous n'avons signalé aucune mutation au codon 540 de pfdhps. Conclusion: Ces résultats montrent une prévalence très faible des polymorphismes de pharmacorésistance connus et suggèrent que les thérapies combinées à base d'artémisinine pourraient conserver une bonne efficacité dans le traitement du paludisme non compliqué au Burkina Faso.

\footnotetext{
*Corresponding authors: afabricesome@yahoo.fr (AF Somé), hsorgho@hotmail.com (H Sorgho)
} 


\section{Background}

In Burkina Faso, malaria is still the most important infectious disease with the highest rates of mortality and morbidity $[17,22]$. Since 2005 , the country has changed its first-line drug for malaria to artemether-lumefantrine (AL) and artesunateamodiaquine (AS-AQ) following reported widespread resistance to chloroquine (CQ), but sulfadoxine-pyrimethamine (SP) is still recommended for chemoprophylaxis in pregnant women [13]. Several studies have since demonstrated the excellent efficacy of artemisinin-based combination therapies (ACTs) for the treatment of uncomplicated malaria in Burkina Faso [30, 37, 38]. However, the emergence of Plasmodium falciparum resistance to artemisinin derivatives in Cambodia [8] represents a serious threat to disease case management, and also to its global control and elimination. The spread of parasite resistance to antimalarial drugs from Asia to Africa has already occurred with CQ and SP [35], suggesting the need for reinforced surveillance of artemisinin resistance in Africa. Several mechanisms of resistance of $P$. falciparum to antimalarial drugs have been reported [14, 34]. For instance, resistance to CQ has been associated with mutations in the gene encoding $P$. falciparum resistance transporter ( $p f c r t)[5,11]$ and a number of mutations in $P$. falciparum multidrug resistance 1 (pfmdrl) $[2,21]$. The same polymorphic traits are also associated with resistance to amodiaquine (AQ) $[6,15]$ and with decreased susceptibility to lumefantrine [7, 24, 25]. In early 2014, artemisinin-resistant phenotypes in Cambodia were associated with mutation in Pf3d7_1343700, one exon gene, which codes for a putative Kelch protein 13 [1]. The identified mutations were associated in vitro with an increased survival rate and in vivo with delayed parasite clearance after artemisinin treatment. One year later, after the identification of artemisinin resistance-mediating mutations, another study clarified the role played by $K 13$ in artemisinin resistance. The authors found that when a K13 mutant parasite was repaired to wild type, the artemisinin resistance was lost; and that conversely, sensitive parasites become more resistant to artemisinin once the wild-type K13 gene is converted to mutant [27].

In West Africa, a study in Dakar, Senegal did not report any mutation between the six blades of K13 [33]. Another study investigating polymorphism in K13 propeller across 12 countries in sub-Saharan Africa identified more than 20 unique mutations. However, this study did not identify any of the mutations reported in south Asia [16].

Although ACTs have demonstrated high efficacy in the treatment of uncomplicated malaria in Bobo-Dioulasso, Burkina Faso, some reports have raised concerns linked to the existence of some selection of antimalarial drug resistance-mediating polymorphisms $[25,26]$. To date, gene polymorphisms in K13 propeller have not been investigated in the Western region of the country, where malaria transmission is holoendemic. In this paper, we aimed to identify the baseline prevalence of known resistance-mediating mutations in the K13 propeller, pfcrt, pfmdrl, pfdhfr, and pfdhps genes in parasites isolated from symptomatic malaria patients in Bobo-Dioulasso, Burkina Faso.

\section{Material and methods}

\section{Study area}

The clinical study was conducted from October to December 2012 in the two peripheral health facilities of Colsama and Sakaby, situated approximately $15 \mathrm{~km}$ away from each other in Bobo-Dioulasso, Burkina Faso. Bobo-Dioulasso is located in the western region of the country where malaria transmission is holoendemic with a peak during the rainy season, approximately August to October, with an estimated entomological inoculation rate (EIR) of 300-500 infective bites per person per year.

\section{Patient and inclusion criteria}

All patients aged 6 months or more and attending Colsama and Sakaby health centers with fever or history of fever in the last $24 \mathrm{~h}$ were referred by a clinician for the screening of malarial infection using Giemsa-stained thick and thin blood smears. Participants with $P$. falciparum infection at parasite densities between 2,000 and 200,000 parasites/ $\mu \mathrm{L}$ and hemoglobin $>5 \mathrm{~g} / \mathrm{dL}$ were included in the clinical study after they or their parent/guardian signed an informed consent form. Other inclusion criteria were: absence of known adverse reactions to study drugs, absence of non-malarial febrile diseases, absence of documented malaria treatment in the last two weeks, and absence of warning signs or severe malaria.

\section{Sample collection and laboratory analysis}

For all patients included in the study, thick and thin smears were collected and stained with $10 \%$ Giemsa on the day of inclusion and at any scheduled or unscheduled visit. Parasite densities were calculated by counting the number of asexual parasites per 200 leukocytes, assuming a leukocyte count of $8,000 / \mu \mathrm{L}$ of blood.

For Polymerase Chain Reaction (PCR) analysis, blood was also collected at the time of inclusion onto filter paper (Whatman 3MM, GE Healthcare), labeled, air-dried, and stored in sealed plastic bags at ambient temperature. Parasite DNA was subsequently extracted using the QIAamp DNA Mini Kit (Qiagen, Germany) according to the Qiagen-DNA purification from dried blood spot protocol [20].

The propeller domain (codons 440-680, $720 \mathrm{bp}$ ) of the K13 gene was amplified by nested PCR using the protocol previously described [1]. For quality control, six P. falciparum strains with known $K 13$ alleles were extracted and analyzed at the same time as study samples. Aliquots of PCR products were analyzed by gel electrophoresis to confirm amplification before sending the remaining PCR products for sequencing at the Wellcome Trust Sanger Institute, Hinxton, United Kingdom. PCR products were sequenced by Macrogen and electropherograms analyzed on both strands using PF3D7_1343700 as the reference sequence. 
Table 1. PCR sensitivity for mutation points analyzed in different Plasmodium falciparum genes.

\begin{tabular}{|c|c|c|c|c|c|c|}
\hline & $K 13$ & Pfcrt k76T & Pfmdrl (Y184F, N86Y) & Pfdhfr (N51I, S108N) & Pfdhfr C59R & Pfdhps $(A 437 G, K 540 E)$ \\
\hline Number of samples & 228 & 244 & 244 & 244 & 244 & 244 \\
\hline Genotyping success $n(\%)$ & $221(96.9)$ & $236(96.7)$ & $238(97.5)$ & $243(99.6)$ & $242(99.2)$ & $237(97.1)$ \\
\hline
\end{tabular}

Single nucleotide polymorphisms (SNPs) in the pfcrt gene at codon 76, pfmdrl at codons 86 and 184, pfdhps at codons 437, 540, and pfdhfr at codons 51, 59, 108, and 164 were assessed using nested PCR, followed by restriction enzyme digestion, as previously described [9, 10]. Digestion products were resolved by gel electrophoresis, and the results were classified as wild type, mixed, or mutant, based on the migration patterns. Samples containing both wild-type and mutant alleles were classified as mutant.

\section{Statistical analysis}

Data were collected with EpiData and analyzed by STATA version 12 (STATA, CA, USA). The count of samples with wild-type and mutant alleles was used to generate the prevalence of the alleles. The chi-square test was used to compare proportions and the statistical significance was defined as a $p$-value, 0.05 .

\section{Ethics}

All the study participants provided informed consent before their enrollment and the study was approved by the institutional Ethics Committee of Centre Muraz, Burkina Faso. All participants received adequate antimalarial treatment.

\section{Results}

A total of 244 samples were collected from patients with uncomplicated $P$. falciparum malaria in two primary health centers of Bobo-Dioulasso. The study population was composed of 111 males and 133 females with a mean age of $26.91 \pm 18.11$ years. The minimum and maximum ages recorded were, respectively, 0.6 and 60 years. The mean body axillary temperature measured prior to blood sampling was $38.51 \pm 1.18{ }^{\circ} \mathrm{C}$ and the mean parasite count was $52,034 \pm 47,590$ trophozoites per $\mu \mathrm{L}$ of blood.

\section{Prevalence of mutation in the $K 13$ propeller}

The gene encoding the propeller domain was successfully sequenced in 221/244 malaria episodes diagnosed from July to December 2012 (Table 1). Using pf3D7_1343700 as the reference strain, we reported $2.26 \%(5 / 221)$ of samples harboring the K13 synonymous mutant alleles (two C469C, one Y493Y, one G496G, and one V589V). SNPs that were associated with in vitro resistance or delayed parasite clearance in Southeast Asia were not observed in Bobo-Dioulasso, nor were any of the polymorphisms observed in parasites from Southeast Asia, nor the M476I mutation that was selected in vitro with artemisinin pressure.

\section{Prevalence of pfdhfr and pfdhps}

The prevalence of pfdhfr 51I, 59R, 108N, and pfdhps 437G mutations was reported, respectively, in $60.9 \%$ (148/243), $53.7 \%(130 / 242), 63.8 \%(150 / 235)$, and $64.0 \%(151 / 236)$ of the samples. We did not find any mutation at codons 164 of pfdhfr and 540 of pfdhps. Triple pure mutant pfdhfr (51, 59, and 108) genes were found in 90 samples and mixed triple mutants in 14 samples (Fig. 1).

\section{Prevalence of pfcrt and pfmdr1}

Among 236 samples successfully amplified for $p f c r t$, a mutation was found at codon K76T in 58/236 (24.6\%) samples. We did not evaluate the pfcrt 72-76 haplotypes in these samples.

Mutations in Pfmdrl N86Y and $Y 184 F$ were identified in $46 / 238(19.3 \%)$ and $167 / 23670.8 \%$ samples, respectively (Fig. 2). We did not genotype three additional mutations in pfmdrl (S1034, N1042, and 1246) that are important elsewhere. These mutations are reported to be uncommon or absent in Burkina Faso throughout the literature.

\section{Discussion}

Despite significant control efforts, malaria remains a major concern in Burkina Faso, with $63.2 \%$ of hospitalizations and $49.6 \%$ of deaths among children under 5 years of age in the country [23] (PNLP, 2014). Our study aimed to evaluate the baseline prevalence of known resistance-mediating mutations in the k13 propeller, pfcrt, pfmdrl, pfdhfr, and pfdhps genes in parasites isolated from symptomatic malaria patients in Bobo-Dioulasso, Burkina Faso. The study is justified by the need for surveillance of $P$. falciparum resistance to antimalarial drugs, in contribution to the monitoring of ACT efficacy in Burkina Faso.

Analysis of K13 propeller did not detect any of the polymorphisms associated with artemisinin resistance in Southeast Asia [1]. Overall, we showed very low prevalence of $k 13$ propeller synonymous mutations. This result is in line with recent studies, which were not able to find any of the polymorphisms associated with artemisinin resistance in sub-Saharan Africa $[16,28]$. The absence of known mutations in the $k 13$ propeller gene augurs favorably for the antimalarial efficacy of ACTs at least in the western part of Burkina Faso with high malaria transmission. Nevertheless, a recent study reported the identification of a unique K13 mutation from Ethiopia [4]. This 


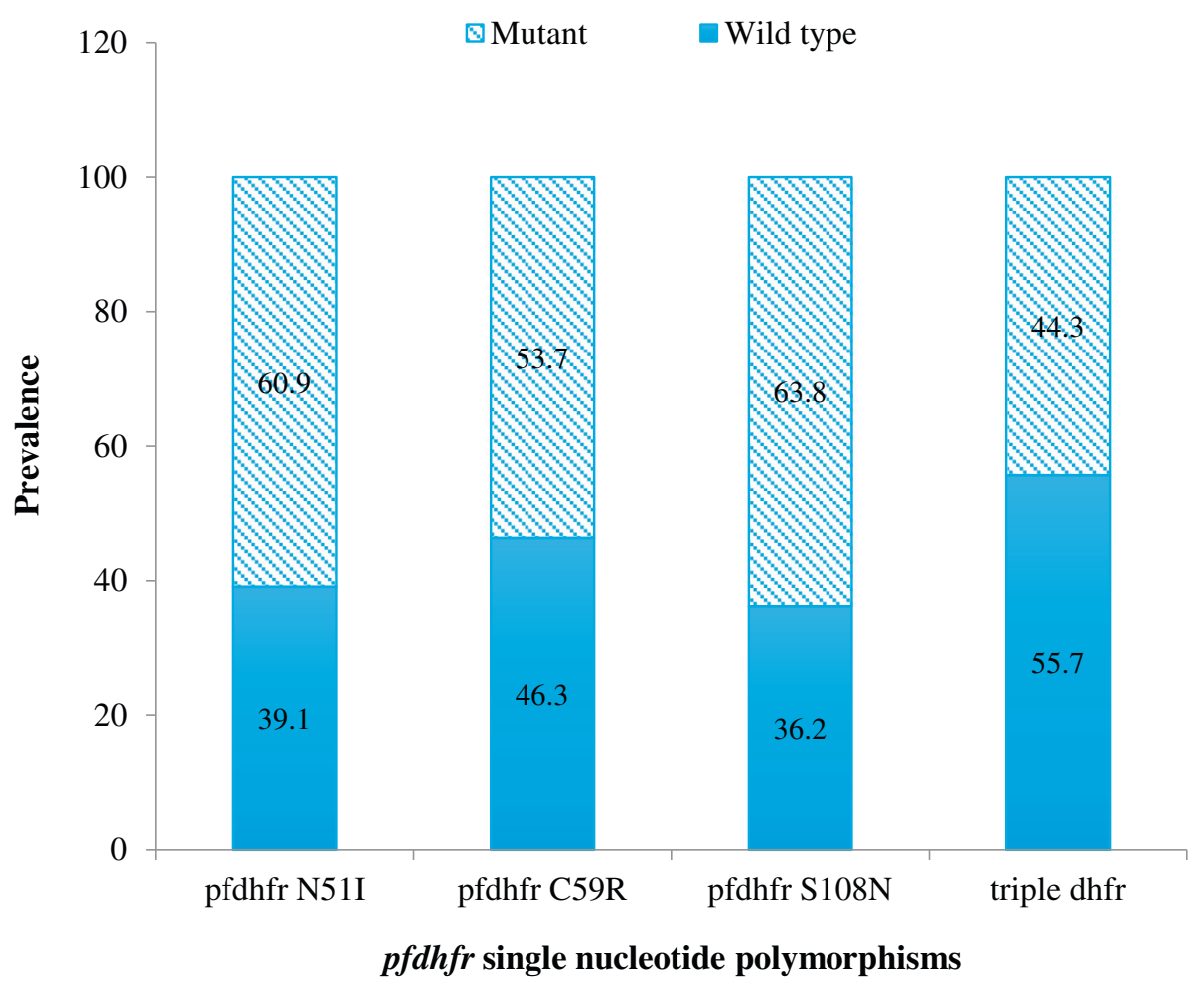

Figure 1. Prevalence of pfdhfr and pfdhps polymorphisms.

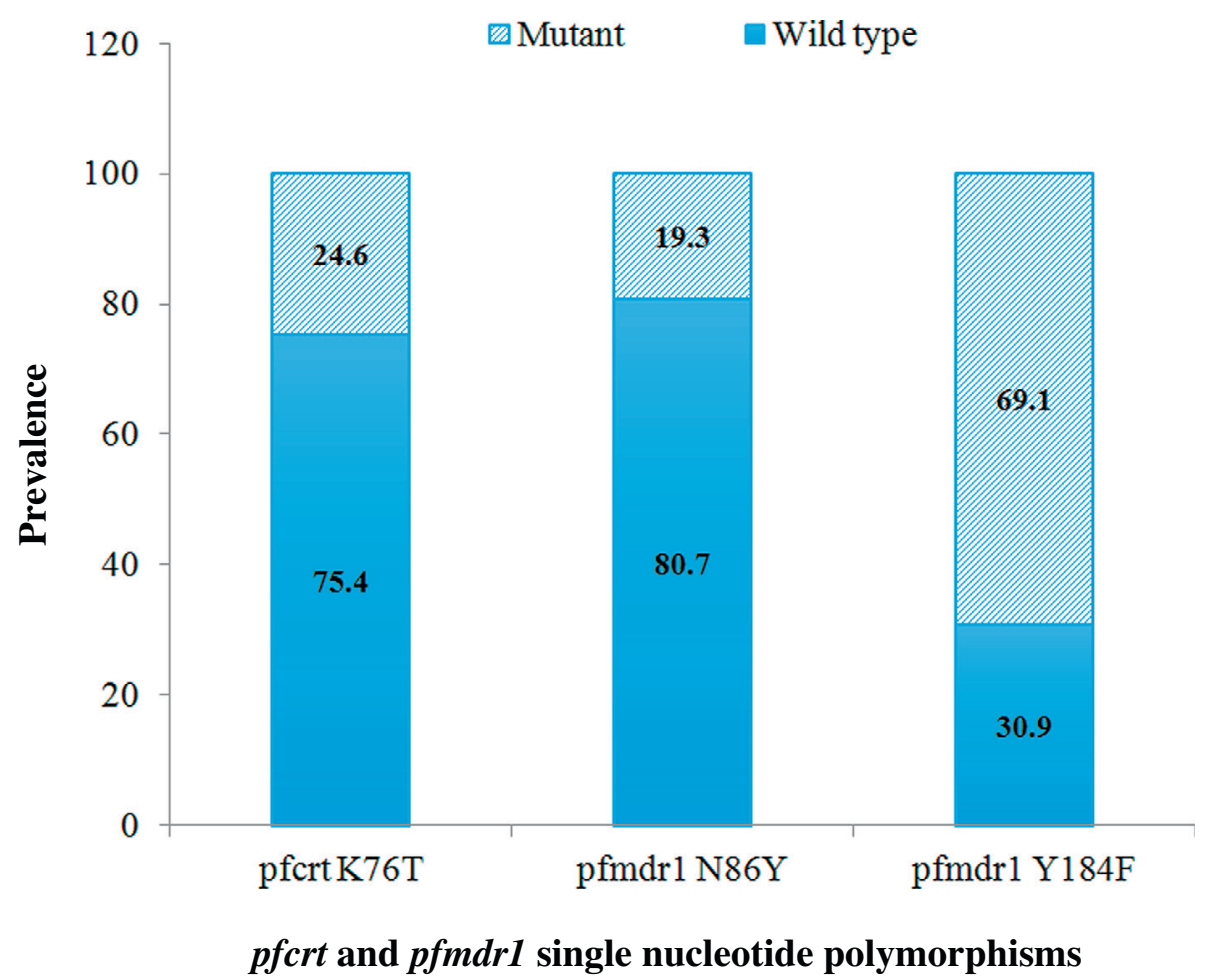

Figure 2. Prevalence of $p f c r t$ and $p f m d r 1$ polymorphisms.

R622I mutation is located on blade 5 of the K13 propeller domain and had not been seen in previous investigations in Africa. More careful monitoring of the evolution of this resistance marker is needed in malaria endemic regions of Africa in order to anticipate countermeasures. In our study, high numbers of undetermined K13 polymorphisms have been 
reported because PCR and/or sequencing failures could not be repeated due to limited funding. This constituted one of the limitations of the study.

Concerning polymorphisms in pfdhfr and pfdhps, which mediate resistance to antifolates, four well-characterized mutations in $p f d h f r(51 \mathrm{I}, 59 \mathrm{R}, 108 \mathrm{~N})$ and $p f d h p s$ (437G) were very common in Bobo-Dioulasso at high prevalence. The presence of mutations at codons 540 of pfdhps and 164 of pfdhfr was not detected in our sample, consistent with previous studies in the subregion [20, 32]. In Burkina Faso, SP is used as monotherapy for intermittent preventive treatment in pregnancy (IPTp) and in association with amodiaquine for seasonal malaria chemoprevention (SMC), which is now being largely implemented in the Sahelian countries. Despite the absence of pfdhps $540 \mathrm{E}$, the high prevalence of mutations reported in pfdhfr (51I, 59R, and $108 \mathrm{~N}$ ) and pfdhps $437 \mathrm{G}$ may jeopardize the efficacy of SP as a tool for malaria control in Burkina Faso. It is therefore very important to continuously monitor the prevalence trend of $p f d h f r$ and $p f d h p s$ mutations for their direct impact on the efficacy of IPTp programs.

For the pfcrt $76 T$ mutation, which is the main determinant of CQ resistance [5], and which is also associated with AQ resistance, we reported a significant decrease of its prevalence as compared to previous studies in Burkina Faso [6, 25, 26, 31]. A similar dramatic decrease in the prevalence of the $p f c r t$ $76 T$ mutation has been reported in Malawi following the withdrawal of CQ for the treatment of malaria [12, 18]. This "chemo-reversion" is interpreted as the result of rapid reexpansion of susceptible parasite strains that survived in semi-immune hosts during the periods of high chloroquine drug pressure [19], and this phenomenon might be accelerated in areas where lumefantrine is currently used [29].

The pfmdrl mutation encodes a predicted food vacuole transporter homologous to $\mathrm{P}$ glycoproteins, which mediate resistance in cancer cells by increasing the efflux of chemotherapeutic agents. For pfmdr1 86Y, the prevalence of wild-type alleles decreased over time in comparison to previous studies $[25,26]$. This result is consistent with recent findings [3] and is likely due to the withdrawal of CQ and the widespread use of AL as first-line antimalarial treatment in the country, which promoted the selection of the wild-type sequences at these alleles $[6,25,26]$. In Burkina Faso, pfmdrl $86 Y$ and AQ resistance has been investigated. The study indicated that pfmdrl could be useful in monitoring AQ resistance [31]. Mutant pfmdrl-184F was most prevalent in our sample but this mutation is not associated with susceptibility to various antimalarial drugs [36]. Although only minor associations with drug susceptibility have previously been observed with polymorphisms at the pfmdr1 $184 F$ locus, one previous study suggests that this allele may also play a role in mediating resistance to some antimalarials [7].

\section{Conclusion}

This study did not find any of the known K13 mutations associated with artemisinin resistance. However, the study reported high prevalence of mutations in $p f d h f r$ and $p f d h$ ps associated with SP resistance. Thus, the use of known molecular markers is fundamental for surveillance in malaria control programs in order to prolong the life span of artemisinin-based combination therapy (ACT) in Africa.

Acknowledgements. We thank the study participants and their parents or guardians for their participation in the study. We also thank the clinical study teams and the health center staff for their continued support and the anonymous reviewer for very helpful comments and reformulation of the manuscript. Finally, we are indebted to Bei Resources for providing control DNA. This study was funded by the National Malaria Control Program of Burkina Faso.

\section{References}

1. Ariey F, Witkowski B, Amaratunga C, Beghain J, Langlois AC, Khim N, Kim S, Duru V, Bouchier C, Ma L, Lim P, Leang R, Duong S, Sreng S, Suon S, Chuor CM, Bout DM, Ménard S, Rogers WO, Genton B, Fandeur T, Miotto O, Ringwald P, Le Bras J, Berry A, Barale JC, Fairhurst RM, Benoit-Vical F, Mercereau-Puijalon O, Ménard D. 2014. A molecular marker of artemisinin-resistant Plasmodium falciparum malaria. Nature, 505, 50-55.

2. Babiker HA, Pringle SJ, Abdel-Muhsin A, Mackinnon M, Hunt P, Walliker D. 2001. High-level chloroquine resistance in Sudanese isolates of Plasmodium falciparum is associated with mutations in the chloroquine resistance transporter gene $p f c r t$ and the multidrug resistance Gene pfmdrl. Journal of Infectious Diseases, 183, 1535-1538.

3. Baraka V, Tinto H, Valea I, Fitzhenry R, Delgado-Ratto C, Mbonye MK, Van Overmeir C, Rosanas-Urgell A, Van Geertruyden JP, D'Alessandro U, Erhart A. 2014. In vivo selection of Plasmodium falciparum Pfcrt and Pfmdrl variants by artemether-lumefantrine and dihydroartemisininpiperaquine in Burkina Faso. Antimicrobial Agents and Chemotherapy, 59, 734-737.

4. Bayih AG, Getnet G, Alemu A, Getie S, Mohon AN, Pillai DR. 2016. A unique Plasmodium falciparum K13 gene mutation in northwest Ethiopia. American Journal of Tropical Medicine and Hygiene, 94, 132-135.

5. Djimdé A, Doumbo OK, Cortese JF, Kayentao K, Doumbo S, Diourté Y, Coulibaly D, Dicko A, Su XZ, Nomura T, Fidock DA, Wellems TE, Plowe CV. 2001. A molecular marker for chloroquine-resistant falciparum malaria. New England Journal of Medicine, 344, 257-263.

6. Dokomajilar C, Lankoande ZM, Dorsey G, Zongo I, Ouedraogo JB, Rosenthal PJ. 2006. Roles of specific Plasmodium falciparum mutations in resistance to amodiaquine and sulfadoxine-pyrimethamine in Burkina Faso. American Journal of Tropical Medicine and Hygiene, 75, 162-165.

7. Dokomajilar C, Nsobya SL, Greenhouse B, Rosenthal PJ, Dorsey G. 2006. Selection of Plasmodium falciparum pfmdrl alleles following therapy with artemether-lumefantrine in an area of Uganda where malaria is highly endemic. Antimicrobial Agents and Chemotherapy, 50, 1893-1895.

8. Dondorp AM, Nosten F, Yi P, Das D, Phyo AP, Tarning J, Lwin KM, Ariey F, Hanpithakpong W, Lee SJ, Ringwald P, Silamut $\mathrm{K}$, Imwong M, Chotivanich K, Lim P, Herdman T, An SS, Yeung S, Singhasivanon P, Day NP, Lindegardh N, Socheat D, White NJ. 2009. Artemisinin resistance in Plasmodium falciparum malaria. New England Journal of Medicine, 361, 455-467. 
9. Dorsey G, Kamya MR, Singh A, Rosenthal PJ. 2001. Polymorphisms in the Plasmodium falciparum pfcrt and pfmdr-1 genes and clinical response to chloroquine in Kampala, Uganda. Journal of Infectious Diseases, 183, 1417-1420.

10. Duraisingh MT, Curtis J, Warhurst DC. 1998. Plasmodium falciparum: detection of polymorphisms in the dihydrofolate reductase and dihydropteroate synthetase genes by PCR and restriction digestion. Experimental Parasitology, 89, 1-8.

11. Fidock DA, Nomura T, Talley AK, Cooper RA, Dzekunov SM, Ferdig MT, Ursos LM, Sidhu AB, Naudé B, Deitsch KW, Su XZ, Wootton JC, Roepe PD, Wellems TE. 2000. Mutations in the $P$. falciparum digestive vacuole transmembrane protein PfCRT and evidence for their role in chloroquine resistance. Molecular Cell, 6, 861-871.

12. Frosch AE, Laufer MK, Mathanga DP, Takala-Harrison S, Skarbinski J, Claassen CW, Dzinjalamala FK, Plowe CV. 2014. Return of widespread chloroquine-sensitive Plasmodium falciparum to Malawi. Journal of Infectious Diseases, 210, $1110-1114$.

13. Gansané A, Nébié I, Soulama I, Tiono A, Diarra A, Konaté AT, Ouédraogo A, Sirima BS. 2009. Change of antimalarial firstline treatment in Burkina Faso in 2005. Bulletin de la Société de Pathologie Exotique, 102, 31-35.

14. Gregson A, Plowe CV. 2005. Mechanisms of resistance of malaria parasites to antifolates. Pharmacological Reviews, 57, 117-145.

15. Happi CT, Gbotosho GO, Folarin OA, Bolaji OM, Sowunmi A, Kyle DE, Milhous W, Wirth DF, Oduola AM. 2006. Association between mutations in Plasmodium falciparum chloroquine resistance transporter and $P$. falciparum multidrug resistance 1 genes and in vivo amodiaquine resistance in $P$. falciparum malaria-infected children in Nigeria. American Journal of Tropical Medicine and Hygiene, 75, 155-161.

16. Kamau E, Campino S, Amenga-Etego L, Drury E, Ishengoma D, Johnson K, Mumba D, Kekre M, Yavo W, Mead D, Bouyou-Akotet M, Apinjoh T, Golassa L, Randrianarivelojosia M, Andagalu B, Maiga-Ascofare O, Amambua-Ngwa A, Tindana P, Ghansah A, MacInnis B, Kwiatkowski D, Djimde AA. 2015. K13-propeller polymorphisms in Plasmodium falciparum parasites from sub-Saharan Africa. Journal of Infectious Diseases, 211, 1352-1355.

17. Kouyaté B, Sie A, Yé M, De Allegri M, Müller O. 2007. The great failure of malaria control in Africa: a district perspective from Burkina Faso. PLoS Medicine, 4, e127.

18. Kublin JG, Cortese JF, Njunju EM, Mukadam RA, Wirima JJ, Kazembe PN, Djimdé AA, Kouriba B, Taylor TE, Plowe CV. 2003. Reemergence of chloroquine-sensitive Plasmodium falciparum malaria after cessation of chloroquine use in Malawi. Journal of Infectious Diseases, 187, 1870-1875.

19. Laufer MK, Takala-Harrison S, Dzinjalamala FK, Stine OC, Taylor TE, Plowe CV. 2010. Return of chloroquine-susceptible falciparum malaria in Malawi was a reexpansion of diverse susceptible parasites. Journal of Infectious Diseases, 202, 801888.

20. Mlambo G, Vasquez Y, LeBlanc R, Sullivan D, Kumar N. 2008. A filter paper method for the detection of Plasmodium falciparum gametocytes by reverse transcription polymerase chain reaction. American Journal of Tropical Medicine and Hygiene, 78, 114-116.

21. Mockenhaupt FP, Teun Bousema J, Eggelte TA, Schreiber J, Ehrhardt S, Wassilew N, Otchwemah RN, Sauerwein RW, Bienzle U. 2005. Plasmodium falciparum dhfr but not dhps mutations associated with sulphadoxine-pyrimethamine treatment failure and gametocyte carriage in northern Ghana. Tropical Medicine \& International Health, 10, 901-908.

22. Mu J, Ferdig MT, Feng X, Joy DA, Duan J, Furuya T, Subramanian G, Aravind L, Cooper RA, Wootton JC, Xiong M, $\mathrm{Su}$ XZ. 2003. Multiple transporters associated with malaria parasite responses to chloroquine and quinine. Molecular Microbiology, 49, 977-989.

23. Programme National de Lutte contre le Paludisme (PNLP), 2014. Directives nationales de prise en charge du paludisme révision de mars 2014. pp. 29.

24. Sisowath C, Strömberg J, Mårtensson A, Msellem M, Obondo C, Björkman A, Gil JP. 2005. In vivo selection of Plasmodium falciparum pfmdr1 $86 \mathrm{~N}$ coding alleles by artemether-lumefantrine (Coartem). Journal of Infectious Diseases, 191, 1014-1017.

25. Somé AF, Séré YY, Dokomajilar C, Zongo I, Rouamba N, Greenhouse B, Ouédraogo JB, Rosenthal PJ. 2010. Selection of known Plasmodium falciparum resistance-mediating polymorphisms by artemether-lumefantrine and amodiaquine-sulfadoxine-pyrimethamine but not dihydroartemisinin-piperaquine in Burkina Faso. Antimicrobial Agents and Chemotherapy, 54, 1949-1954.

26. Somé AF, Zongo I, Compaoré YD, Sakandé S, Nosten F, Ouédraogo JB, Rosenthal PJ. 2014. Selection of drug resistance-mediating Plasmodium falciparum genetic polymorphisms by seasonal malaria chemoprevention in Burkina Faso. Antimicrobial Agents and Chemotherapy, 58, 3660-3665.

27. Straimer J, Gnädig NF, Witkowski B, Amaratunga C, Duru V, Ramadani AP, Dacheux M, Khim N, Zhang L, Lam S, Gregory PD, Urnov FD, Mercereau-Puijalon O, Benoit-Vical F, Fairhurst RM, Ménard D, Fidock DA. 2015. K13-propeller mutations confer artemisinin resistance in Plasmodium falciparum clinical isolates. Science, 347, 428-431.

28. Taylor SM, Parobek CM, DeConti DK, Kayentao K, Coulibaly SO, Greenwood BM, Tagbor H, Williams J, Bojang K, Njie F, Desai M, Kariuki S, Gutman J, Mathanga DP, Mårtensson A, Ngasala B, Conrad MD, Rosenthal PJ, Tshefu AK, Moormann AM, Vulule JM, Doumbo OK, Ter Kuile FO, Meshnick SR, Bailey JA, Juliano JJ. 2014. Absence of putative artemisinin resistance mutations among Plasmodium falciparum in SubSaharan Africa: a molecular epidemiologic study. Journal of Infectious Diseases, 211, 680-688.

29. Thomsen TT, Madsen LB, Hansson HH, Tomás EV, Charlwood D, Bygbjerg IC, Alifrangis M. 2013. Rapid selection of Plasmodium falciparum chloroquine resistance transporter gene and multidrug resistance gene-1 haplotypes associated with past chloroquine and present artemetherlumefantrine use in Inhambane District, Southern Mozambique. American Journal of Tropical Medicine and Hygiene, 88, 536-541.

30. Tinto H, Diallo S, Zongo I, Guiraud I, Valea I, Kazienga A, Kpoda H, Sorgho H, Ouédraogo JB, Guiguemdé TR, D'Alessandro U. 2014. Effectiveness of artesunateamodiaquine $v s$. artemether-lumefantrine for the treatment of uncomplicated falciparum malaria in Nanoro, Burkina Faso: a non-inferiority randomised trial. Tropical Medicine \& International Health, 19, 469-475.

31. Tinto H, Guekoun L, Zongo I, Guiguemdé RT, D'Alessandro U, Ouédraogo JB. 2008. Chloroquine-resistance molecular markers (Pfcrt T76 and Pfmdr-1 Y86) and amodiaquine resistance in Burkina Faso. Tropical Medicine \& International Health, 13, 238-240. 
32. Tinto H, Ouédraogo JB, Zongo I, van Overmeir C, van Marck E, Guiguemdé TR, D'Alessandro U. 2007. Sulfadoxine-pyrimethamine efficacy and selection of Plasmodium falciparum DHFR mutations in Burkina Faso before its introduction as intermittent preventive treatment for pregnant women. American Journal of Tropical Medicine and Hygiene, 76, 608-613.

33. Torrentino-Madamet M, Fall B, Benoit N, Camara C, Amalvict R, Fall M, Dionne P, Ba Fall K, Nakoulima A, Diatta B, Diemé Y, Ménard D, Wade B, Pradines B. 2014. Limited polymorphisms in k13 gene in Plasmodium falciparum isolates from Dakar, Senegal in 2012-2013. Malaria Journal, 13, 472.

34. Woodrow CJ, Krishna S. 2006. Antimalarial drugs: recent advances in molecular determinants of resistance and their clinical significance. Cellular and Molecular Life Sciences, 63, 1586-1596.

35. Wootton JC, Feng X, Ferdig MT, Cooper RA, Mu J, Baruch DI, Magill AJ, Su XZ. 2002. Genetic diversity and chloroquine selective sweeps in Plasmodium falciparum. Nature, 418, $320-323$.
36. Wurtz N, Fall B, Pascual A, Fall M, Baret E, Camara C, Nakoulima A, Diatta B, Fall KB, Mbaye PS, Diémé Y, Bercion R, Wade B, Pradines B. 2014. Role of Pfmdrl in in vitro Plasmodium falciparum susceptibility to chloroquine, quinine, monodesethylamodiaquine, mefloquine, lumefantrine, and dihydroartemisinin. Antimicrobial Agents and Chemotherapy, 58, 7032-7040.

37. Zongo I, Dorsey G, Rouamba N, Dokomajilar C, Séré Y, Rosenthal PJ, Ouédraogo JB. 2007. Randomized comparison of amodiaquine plus sulfadoxine-pyrimethamine, artemetherlumefantrine, and dihydroartemisinin-piperaquine for the treatment of uncomplicated Plasmodium falciparum malaria in Burkina Faso. Clinical Infectious Diseases, 45, 1453-1461.

38. Zongo I, Dorsey G, Rouamba N, Tinto H, Dokomajilar C, Guiguemde RT, Rosenthal PJ, Ouedraogo JB. 2007. Artemether-lumefantrine versus amodiaquine plus sulfadoxinepyrimethamine for uncomplicated falciparum malaria in Burkina Faso: a randomised non-inferiority trial. Lancet, 369, 491-498.

Cite this article as: Somé AF, Sorgho H, Zongo I, Bazié T, Nikiéma F, Sawadogo A, Zongo M, Compaoré Y \& Ouédraogo J: Polymorphisms in K13, pfcrt, pfmdrl, pfdhfr, and pfdhps in parasites isolated from symptomatic malaria patients in Burkina Faso. Parasite, 2016, 23, 60 .

Reviews, articles and short notes may be submitted. Fields include, but are not limited to: general, medical and veterinary parasitology; morphology, including ultrastructure; parasite systematics, including entomology, acarology, helminthology and protistology, and molecular analyses; molecular biology and biochemistry; immunology of parasitic diseases; host-parasite relationships; ecology and life history of parasites; epidemiology; therapeutics; new diagnostic tools.

All papers in Parasite are published in English. Manuscripts should have a broad interest and must not have been published or submitted elsewhere. No limit is imposed on the length of manuscripts.

Parasite (open-access) continues Parasite (print and online editions, 1994-2012) and Annales de Parasitologie Humaine et Comparée (1923-1993) and is the official journal of the Société Française de Parasitologie. 